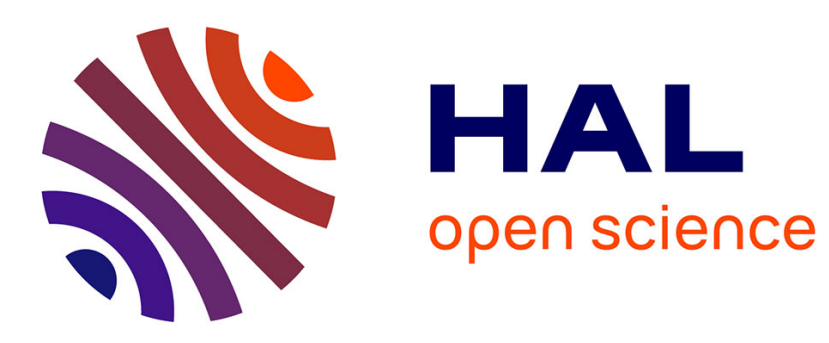

\title{
Trade-off-based Adoption Methodology for Cloud-Based Infrastructures and Services
}

\author{
Radhika Garg, Burkhard Stiller
}

\section{To cite this version:}

Radhika Garg, Burkhard Stiller. Trade-off-based Adoption Methodology for Cloud-Based Infrastructures and Services. 8th IFIP International Conference on Autonomous Infrastructure, Management and Security (AIMS), Jun 2014, Brno, Czech Republic. pp.1-14, 10.1007/978-3-662-43862-6_1 . hal01401280

\section{HAL Id: hal-01401280 \\ https://hal.inria.fr/hal-01401280}

Submitted on 23 Nov 2016

HAL is a multi-disciplinary open access archive for the deposit and dissemination of scientific research documents, whether they are published or not. The documents may come from teaching and research institutions in France or abroad, or from public or private research centers.
L'archive ouverte pluridisciplinaire HAL, est destinée au dépôt et à la diffusion de documents scientifiques de niveau recherche, publiés ou non, émanant des établissements d'enseignement et de recherche français ou étrangers, des laboratoires publics ou privés. 


\title{
Trade-off-based Adoption Methodology for Cloud-based Infrastructures and Services
}

\author{
Radhika Garg, Burkhard Stiller \\ Department of Informatics IFI, University of Zurich, Switzerland. \\ \{garg|stiller\}@ifi.uzh.ch
}

\begin{abstract}
Adoption and consequent management of cloud-based infrastructures and services is driven by business requirements and objectives within an organization. The decision of either to move from a legacy system to a cloudbased system or to move from one cloud solution to another is based on various factors. A potential customer, therefore, should evaluate (a) relevant factors affecting the adoption of a cloud and (b) impacts cloud services will have on multi-faceted objectives of an organization. Existing methods for such an adoption process do not evaluate these two aspects for the decision of cloud adoption. Thus, this paper fills this gap by introducing a new Trade-off-based Adoption methodology for Cloud-based Infrastructures and Services (TrAdeCIS), which is based on the impact cloud-based services will have on the organization. This methodology developed will support organizations in decisions concerning (a) the selection of cloud service provider, (b) the type of cloud service to be adopted, and (c) the suitable type of cloud to be adopted. TrAdeCIS is illustrated based on a survey conducted with 10 organizations, who have adopted or plan to adopt cloud-based solution to fulfil their advanced IT requirements.
\end{abstract}

\section{Introduction}

Organizations are increasingly concentrating on adopting new and emerging IT solutions to fulfill their business requirements and objectives. A cloud computing environment foresees advantages for organizations such as lower IT administration and managed service costs and a better business continuity and disaster recovery process [1], [13]. However, there are also disadvantages in terms of loss of control of services and/or data [19] as well as lower security, privacy, and reliability [9], [10]. Therefore, in a decision of either moving from a legacy infrastructure to a cloud-based solution or switching the cloud provider, contradicting and interdependent factors must be evaluated in full. These factors can be based on technical, economical, legal, and business oriented requirements and objectives. The difficulty in the decision of cloud adoption exists because of multiple criteria of selection, and due to the presence of more than one alternative solution. The current decision methodology for the selection of the best available cloud-based solution for IT requirements in organizations is an ad-hoc process, which does not only fail to achieve a trade-off between multiple contradicting factors, but also lacks a quantitative validation of this decision made.

Researchers have suggested a generic framework for such a decision using multiattribute decision algorithms [14], [16]. However, this work did not incorporate that 
(a) attributes can be mutually dependent, and (b) a trade-off-based decision is required based on multi-faceted business objectives. Hence, the need of a highly integrated yet flexible methodology for the decision of cloud adoption was distinctly identified [22]. The methodology developed and followed in this paper is called Trade-off-based Adoption methodology for Cloud-based Infrastructures and Services (TrAdeCIS) and is motivated by those gaps still existent in terms of identifying tradeoff strategies for a cloud adoption and the management of cloud-based infrastructures and services. Trade-off strategy means altering the importance allotted to business objectives so that the best possible technical solution, based on traditional IT metrics, such as availability, response time, scalability, or efficiency, can be selected. Therefore, the methodology discussed in this paper focuses on the impact of business processes and business-level objectives on cloud adoption and vice versa. The aim of this approach is to find the best possible technical solution on an acceptable business value. This methodology can be used for a cloud-based decision concerning cloud-service providers, the cloud type, and services that should be migrated to the cloud. The application case of cloud-based solutions, has been selected due to its current importance, the demand from companies to see guided help, and to formalize the methodolgy in a concrete setting.

The methodology developed in this paper consists of following three steps: First, the identification of relevant factors, based on which the available alternative solutions will be evaluated. The list of such factors for this paper is retrieved based on the survey conducted with organizations who plan or have adopted cloud-based solutions for their IT needs. The following two steps of the decision support system are based on two multi-criteria decision analysis methods: (a) The Technique for Order of Preference by Similarity to Ideal Solution (TOPSIS), and (b) the Analytic Network Process (ANP) [12], [17]. These two methods are chosen due to their inherent nature of being able to compare components of an adoption scenario and to rank alternatives under consideration. While TOPSIS is used to rank alternative solutions based on technical requirements, ANP is used to establish a trade-off-based decision for multiple contradicting Business Performance Metrics. These algorithms will be used within the envelope of business-level objectives, so that a holistic method is achieved for the decision regarding adoption of cloud.

This paper is structured as follows. Sec. 2 discusses relevant research work and gaps existent in a cloud adoption process. Sec. 3 provides an in-depth view of TrAdeCIS for establishing the trade-off-based decision methodology for adoption of clouds in an organization. Sec. 4 illustrates the new methodology based on results obtained from the survey conducted. Finally, Sec. 5 summarizes and concludes the paper.

\section{Terminology and Related Work}

Business-driven IT management deals with fulfilling IT requirements by evaluating impact of IT on business processes and vice versa. However, business objectives are contradicting in nature and, therefore, a trade-off strategy is necessary. Such a strategy can fulfil IT requirements in a best possible way by balancing various requirements and goals. The term business value or return value refers to the impact IT (in 
the context of this paper, a cloud-based solution) has on organizational performance using process-level, economic, and operational metrics, called Business Performance Metrics (BPM).

In order to compare related work to TrAdeCIS, it is divided into two groups. Category one consists of current efforts in cloud adoption and management of cloud resources and services concentrating on technical aspects, such as resource provisioning [7] or migration and implementation processes [4], [11]. Category two comprises of methodologies for the decision of cloud adoption for an organization. Research on a cloud adoption decision process suggests various approaches such as Goal-oriented Requirement Engineering (GRE) [22], [2] and a quantified method of Multi-Attribute Decision Analysis (MADA) [14], [16]. These approaches present a method of decision making based on evaluating various factors that impact such a decision. However, they are not integrated and do not incorporate business-level objectives and requirements. For example, the effect on the net profit after adopting cloud-based services cannot be addressed by such methods.

However, from the cloud providers perspective, the last few years have seen research on business-driven IT management [5], [8], [18]. These approaches concentrate on managing the ever increasing scale of cloud-based resources and services, by providing business level objectives-driven cloud management for the cloud provider. These are holistic approaches as cloud providers have to consider the context where services are used in order to make any service management related decision.

As shown in Tab. 1 the comparison of related work to TrAdeCIS is based on four key features, "Yes" describing the presence and "No" denoting the lack of that feature.

Table 1. Feature Comparison of Cloud Implementation and Adoption Methods

\begin{tabular}{|l|l|l|l|l|}
\hline Features & $\begin{array}{l}\text { Implementation } \\
\text { Methods }\end{array}$ & MADA & GRE & TrAdeCIS \\
\hline Relevant Factor Identification Method & No & No & Yes & Yes \\
\hline Quantified Decision Method & No & Yes & No & Yes \\
\hline Business Objectives Consideration & No & No & No & Yes \\
\hline Trade-off-based decision & No & No & No & Yes \\
\hline
\end{tabular}

A cloud adoption decision methodology based not only on monitoring technical requirements and factors but also targeting to reach a overall governance process, itself based on business-level policies and objectives, does not exist for a potential cloud customer. The overall adoption decision for a cloud becomes more complex when services and resources are distributed in diverse legacy infrastructure.

Therefore, TrAdeCIS establishes a novel methodology, with which an organization can take a decision based on a trade-off strategy of business objectives. TOPSIS and ANP serve as underlying mathematical models to support this decision of establishing a trade-off strategy. The capability of ANP and TOPSIS to work with interdependent and conflicting factors, effecting the decision, qualifies them to be applicable. Both methods have also been used for solving decision problems with certainty and making forecasts in various fields of science, manufacturing, and finance [6], [15], [21]. 


\section{The Development of TrAdeCIS}

The overview of the methodology developed in this paper to establish trade-off-based decision for the selection of (a) cloud service provider, (b) cloud service to be adopted, and (c) the suited type of cloud to be adopted, is shown in Fig. 1. As the decision to move from legacy infrastructure to cloud-based solution or to switch the cloud provider is effected by several factors, TrAdeCIS begins with the selection and prioritization of these factors. The selection and prioritization of these factors is based on the technical requirements, and business objectives and policies of organization. Once TrAdeCIS is implemented as a decision support tool, it will include a generalized list of factors, which organizations planning to adopt cloud-based solutions should consider. This list of factors will be based on data collected from (a) survey conducted with organizations who have adopted or plan to adopt cloud-based solution, and (b) academic and industry literature on relevant factors in such a scenario. However, TrAdeCIS would provide flexibility to the organizations to adapt this list of factors based on use-case specific details. This process of identification and prioritizing factors is discussed and presented in Sec. 4. Once an organization identifies its requirements and business objectives TrAdeCIS is an easy, efficient, and a structured approach for making a decision for adoption of cloud-based solutions, which involv multiple attributes and objectives. This is possible because TrAdeCIS is a fully quantitative approach based on mathematical models with clearly identified steps.

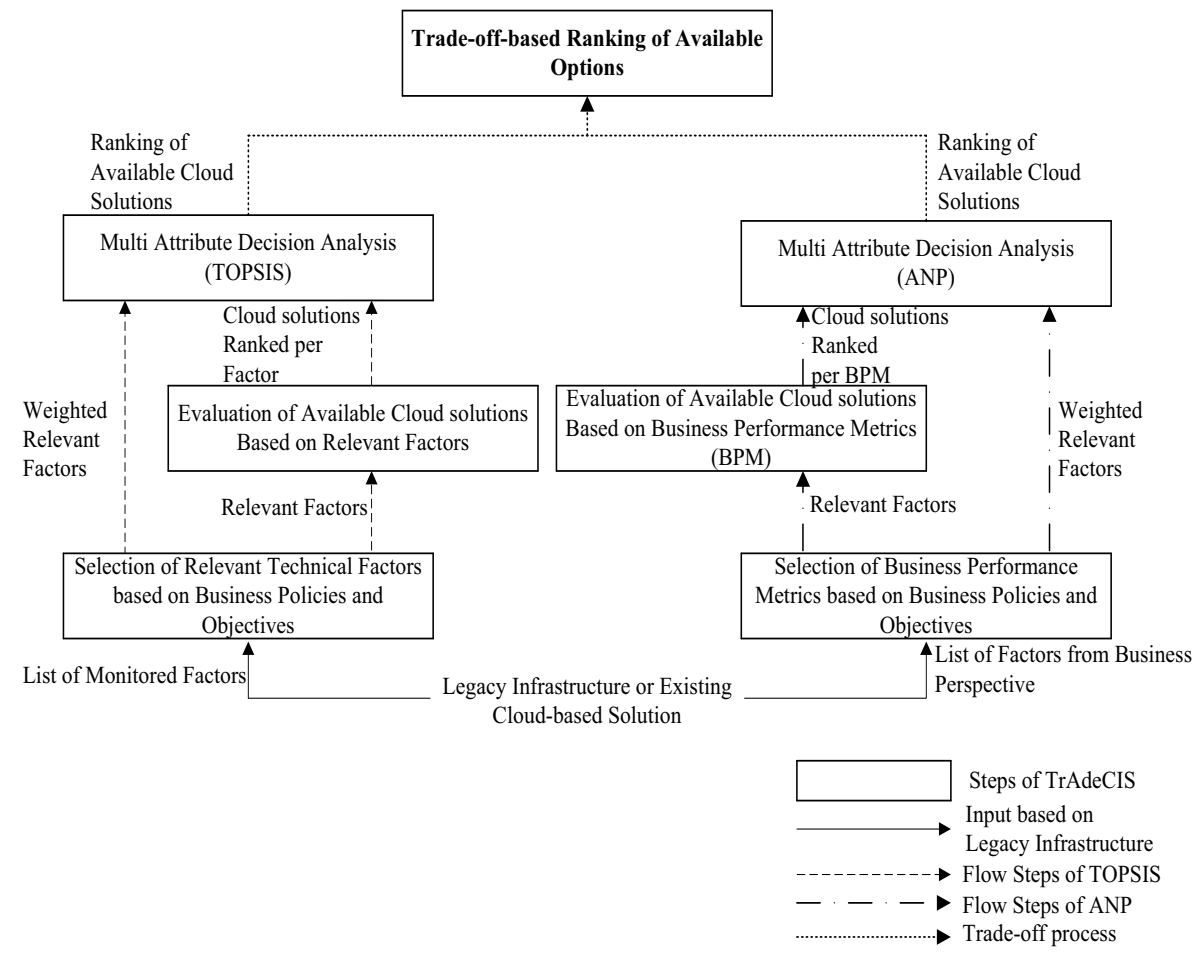

Fig. 1. Methodology for Business Driven Trade-off-based Decision for Cloud Adoption 


\subsection{Business Layer}

The first step for making a decision for the adoption of a cloud-based solution is driven by business level considerations of an organization who plans to a adopt cloudbased solution. Based on the status of current infrastructure (e.g., resources, processes interdependencies), and business goals and policies (e.g., availability level, risk) relevant factors for the evaluation of alternative new cloud-based solutions are selected. To illustrate the process of selection of relevant factors consider an organization dealing with private information of its clients. Such an organization will target to have a control over such data to make sure data is not lost and tampered by anybody. Therefore, privacy of data and data control are two most important factors to be considered. Criteria which serve as benefits are considered positive (e.g., bandwidth, availability) while those which are risk or cost prone are considered to be negative (e.g., latency, cost) [14]. Also, depending on the criticality of the business goal,selected on the basis of business policies, relevant factors can be given a relative rank. Criticality of business goals is a metric to define the relevance as it is defined in an organization for each process and service for evaluating IT operations, for example, in terms of, risk in terms of vendor lock-in, technical requirements of availability, latency, security, and business goals and vision of reducing operational cost, increasing available resources.

\subsection{TOPSIS}

Once relevant factors are identified and prioritized a multi-attribute decision making algorithm is required to rank alternative solutions. TOPSIS is such a technique for solving decision problems by determining the relative advantage of available alternatives [12]. An optimum alternative is mathematically at the shortest geometrical distance from the best solution and at largest geometrical distance from the worst solution. The alternative solution that is at the maximum distance from the worst solution has the least risk attached to it. With this method it is possible to compare a set of alternatives by identifying priorities for each factor and normalizing score for each factor. This gives the advantage of identifying how an alternative scores per attribute in form of the following steps:

1. TOPSIS assumes that there are $m$ alternatives and $n$ attributes/criteria and the score of each option with respect to each criterion is known [20]. Let $\mathrm{X}=(\mathrm{xij})$ and $\mathrm{m} \times \mathrm{n}$ a matrix represent $\mathrm{xij}$ the score of alternative $\mathrm{i}$ with respect to criterion $\mathrm{j}$. Let $\mathrm{J}$ be the set of benefit attributes (to be maximized) and $\mathrm{J}$ ' be the set of negative attributes or criteria (to be minimized).

2. The matrix $X$ is normalized to form a normalized decision matrix. This step transforms the attributes having different dimensions into non-dimensional attributes, hence allowing comparisons across criteria. Normalized weights are obtained as

$$
\mathrm{r}_{\mathrm{ij}}=\frac{\mathrm{x}_{\mathrm{ij}}}{\sum_{\substack{1 \leq \mathrm{i} \leq \mathrm{m} \\ 1 \leq \mathrm{j} \leq \mathrm{n}}} \mathrm{x}_{\mathrm{ij}}^{2}}
$$


3. Construct the weighted normalized decision matrix, where each weight is represented by wj for $1 \leq \mathrm{j} \leq \mathrm{n}$. Multiply each column of the normalized decision matrix by its associated weight. An element of the new decision matrix is $\mathrm{v}_{\mathrm{ij}}=\mathrm{w}_{\mathrm{ij}} \times \mathrm{r}_{\mathrm{ij}}$.

4. Determine the ideal positive solution $A^{*}=\left[v_{1}{ }^{*}, v_{n}{ }^{*}\right]$, where $v_{j}{ }^{*}=\max \left(v_{i j}\right)$, if $\mathrm{j} \in \mathrm{J}$ or $\min \left(\mathrm{v}_{\mathrm{ij}}\right)$ if $\mathrm{j} \in \mathrm{J}^{\prime}$. Determine the ideal negative solution $\mathrm{A}^{\prime}=\left[\mathrm{v}_{1}{ }^{1}, \mathrm{v}_{\mathrm{n}}{ }^{\prime}\right]$, where $v_{j}^{\prime}=\min \left(v_{i j}\right)$, if $j \in J$ or $\max \left(v_{i j}\right)$ if $j \in J^{\prime}$.

5. Determine the separation from the ideal solution for every alternative $j$. Distance from the positive solution is $\mathrm{S}_{\mathrm{i}}{ }^{*}=\sqrt{\sum\left(\mathrm{v}_{\mathrm{j}}{ }^{*}-\mathrm{v}_{\mathrm{ij}}\right)^{2}}$ and that from the negative solution is $S_{i}^{\prime}=\sqrt{\sum\left(v_{j}^{\prime}-v_{i j}\right)^{2}}$ for $1 \leq j \leq m$. 6. Calculate the relative closeness to the ideal solution $\mathrm{C}_{\mathrm{i}}{ }^{*}=\frac{\mathrm{S}_{\mathrm{i}}}{\mathrm{S}_{\mathrm{i}}{ }^{*}+\mathrm{S}_{\mathrm{i}}{ }^{\prime}}$. Give highest
rank to the option with $\mathrm{C}_{\mathrm{i}}{ }^{*}$ closest to 1 .

Using this method TrAdeCIS obtains a ranked list of available alternative cloudbased solutions, which are evaluated on technical parameters based on business objectives and policies as shown in Sec. 4.2.

\subsection{Evaluation of Alternatives Based on Business Performance Metrics}

While the alternative solutions, in the previous step, were ranked based on the relevant factors from the technical and operations perspective, this step evaluates the alternative solutions from the business value perspective. This is important so that returns in terms of business value can be quantified and measured for each of the alternatives. These factors fall in the category of cost, time, profitability, or quality, for example, earned value, planned dollar expenditure per month, workload vs. utilization, and speed of cost reduction. Therefore, based on the business objectives and policies, appropriate BPM are identified and ranked. Each alternative is then evaluated for each of these metrics.

\subsection{Trade-off-based Decision using ANP}

The final step is the most crucial step as it lets decision makers evaluate alternative solutions from the perspective of a return value. ANP evaluates the decision by considering the interdependence of attributes as well as the influence of alternatives in a decision making process [17]. The ranking obtained here can be different than the one obtained from TOPSIS. This happens because factors used to evaluate alternatives in ANP are BPMs as identified by organizations. ANP provides the flexibility of altering weights allotted to factors to establish a trade-off in TrAdeCIS. Establishing a trade-off is necessary so that the best technical solution is selected at an acceptable return value. The possibility of calculating the interdependence of attribute and ability to forecast benefits, costs, and risks qualify ANP for establishing a trade-off strategy for cloud adoption. In this method criteria and alternatives are considered as nodes in a network as shown in Fig. 2. Each node can be compared to all other nodes it has a relation with, thus, a logical overview of those steps is given here only [17]: 
1. ANP makes a pare wise comparison of all nodes with respect to the objective. An equally spaced scale is also chosen to assign priorities.

2. These priorities are represented in a matrix and the normalized principle Eigen vector is computed. As a result local priorities for all connections are obtained.

3. Steps 1 and 2 are repeated for all connections to obtain the unweighted super matrix.

4. The unweighted super matrix is normalized to calculate the weighted super matrix.

5. The limit matrix is now calculated, which is the weighted super matrix raise to the power of $\mathrm{k}+1$, where $\mathrm{k}$ is an arbitrary positive integer. This gives the ranking for alternative solutions with respect to the objective.

After applying ANP, a ranking of alternatives is obtained, which is based on the evaluation of available alternative solutions on the basis of BPMs identified by organizations. In this step, if the ranking obtained is different from the one obtained using TOPSIS (as different factors are considered), priorities given to factors can be adjusted in order to achieve the same ranking as with TOPSIS. These priorities represent the trade-off between the return value and technical features of a selected solution.

\section{$4 \quad$ Illustration of the Method Based on Survey Results}

This section illustrates the new methodology using parameters and their respective weights, based on interviews conducted with 10 organizations, who adopted or plan to adopt a cloud-based solution to fulfil their IT requirements. A qualitative research approach is followed in order to investigate diverse and complex data in depth [3].

Table 2. Organizations Overview

\begin{tabular}{|l|l|l|l|}
\hline Company & Domain of Expertise & $\begin{array}{l}\text { Size of } \\
\text { Company }\end{array}$ & Geographic Scope Served \\
\hline C1 & ICT Provider & 60000 & Europe, USA, Singapore \\
\hline C2 & Health Insurance & 450 & Switzerland \\
\hline C3 & Telecommunications & 20000 & Switzerland \\
\hline C4 & IT Infrastructure provider & 5000 & Europe, USA, Australia, China \\
\hline C5 & Financial Services & 2600 & Worldwide \\
\hline C6 & $\begin{array}{l}\text { Property and Life } \\
\text { Insurance }\end{array}$ & 4000 & Switzerland \\
\hline C7 & Professional Services & 180000 & Worldwide \\
\hline C8 & Networking Solutions & 67000 & Worldwide \\
\hline C9 & ICT Association & - & Switzerland \\
\hline C10 & Financial Services & 140000 & Worldwide \\
\hline
\end{tabular}

a number of employees as per June, 2013

As shown in Tab. 2, organizations that participated in the survey vary in size, the scope of their expertise, and their geographical scope. Therefore, their IT requirements also vary. In turn, the aim of these interviews was to understand parameters 
these organizations evaluate before making a decision to make any changes in their existing IT infrastructure. These interviews were semi-structured so that those interviews could be adapted according to individual circumstances, such as focusing on specific areas or discarding questions, which did not apply. This survey helped in collecting a list of factors (e.g., availability, functionality, scalability), which depending on the use-case specific details were considered by organizations before adopting any cloud-based solution. In order to illustrate TrAdeCIS only the data collected from company $C 2$ is used. This helps in evaluating a specific use-case in depth using TrAdeCIS. However, this methodology can be applied to any of the other use-case specific data obtained from other organizations. All the other use-cases are that of similar nature, and discussing them in depth would not provide any new insights to the illustration of TrAdeCIS. The plan of $C 2$ is to scale the existing infrastructure in order to accommodate requirements of the peak season. Therefore, $C 2$ required to evaluate the best available cloud-service provider.

\subsection{Business Layer}

Business requirements for $C 2$ were to increase scalability and availability of the existing infrastructure as the business profitability depends mainly on the web-based platforms and applications that are used by customers and partners of $C 2$. Also, as these applications dealt mainly with private and sensitive data of clients, privacy and security were also important aspects. In addition, as per the legal and regulative requirements, compliance and location of data storage were also critical factors for evaluating the alternative cloud-based solutions. After, finding the list of factors, C2 was asked to give both the weights of attributes and ranking of alternatives by numbers in the range of 1 to 10. As TOPSIS normalizes weights and rankings, the range and the number chosen to rank the alternatives does not matter, as shown in Sec. 4.2., These factors along with their relevant priorities (as identified by C2) are shown in Tab. 3. This table also consists of ranking of each of the available alternative service providers (A1, A2, A3) per factor, which were being considered by $C 2$.

Table 3. Ranking of Alternatives per Attribute

\begin{tabular}{|l|l|l|l|l|}
\hline Factors & Weights & A1 & A2 & A3 \\
\hline Functionality & 3 & 7 & 6 & 5 \\
\hline Privacy & 7 & 9 & 4 & 10 \\
\hline Availability & 6 & 4 & 3 & 2 \\
\hline Scalability & 5 & 5 & 8 & 5 \\
\hline Compliance & 4 & 1 & 2 & 3 \\
\hline Storage Location & 2 & 3 & 1 & 6 \\
\hline Simplicity & 1 & 4 & 2 & 7 \\
\hline
\end{tabular}

\subsection{Ranking the Alternative Solutions using TOPSIS}

Alternatives are ranked in TOPSIS on the basis of distance from positive ideal and negative ideal solution as explained in Sec. 3.2. Applying formal steps of TOPSIS on 
the data shown in Tab. 3 positive ideal and negative solutions are calculated as shown in Tab. 4.

While the positive ideal solution is the set of the maximum values $\{2.001,4.988$, $4.460,2.340,1.068,2.356,0.843\}$ for all these factors amongst all alternatives, the negative ideal solution is the set of minimum values $\{1.410,1.995,2.230,3.745$, $3.208,0.388,0.240\}$.

Table 4. Positive Ideal Solution and Negative Ideal

\begin{tabular}{|l|l|l|l|}
\hline Factors & A1 & A2 & A3 \\
\hline Functionality & 2.001 & 1.710 & 1.410 \\
\hline Privacy & 4.489 & 1.995 & 4.988 \\
\hline Availability & 4.460 & 3.342 & 2.230 \\
\hline Scalability & 2.340 & 3.745 & 2.340 \\
\hline Compliance & 1.068 & 2.136 & 3.208 \\
\hline Storage Location & 1.178 & 0.388 & 2.356 \\
\hline Simplicity & 0.481 & 0.240 & 0.843 \\
\hline
\end{tabular}

In these sets element 4 and 5 , namely scalabilty and compliance, are considered to be negative factors, i.e., they contribute to risk and cost of the decision. Therefore, in the positive ideal set maximum value is taken and in the negative ideal solution minimum value is considered. The next step of TOPSIS is to find the distance of the alternative solutions from the positive and negative ideal solutions as shown in Tab. 5 and Tab. 6 .

Table 5. Distance from the Positive Ideal Solution

\begin{tabular}{|l|l|l|l|}
\hline Factors & A1 & A2 & A3 \\
\hline Functionality & 0.000 & 0.073 & 0.3111 \\
\hline Privacy & 0.201 & 8.883 & 0.000 \\
\hline Availability & 0.000 & 0.553 & 2.166 \\
\hline Scalability & 0.000 & 1.625 & 0.000 \\
\hline Compliance & 0.000 & 0.531 & 2.133 \\
\hline Storage Location & 0.723 & 1.999 & 0.000 \\
\hline Simplicity & 0.117 & 0.324 & 0.000 \\
\hline $\mathrm{S}_{\mathrm{i}}{ }^{*}$ & 1.009 & 3.740 & 2.147 \\
\hline
\end{tabular}

Table 6. Distance from the Negative Ideal Solution

\begin{tabular}{|l|l|l|l|}
\hline Factors & A1 & A2 & A3 \\
\hline Functionality & 0.311 & 0.083 & 0.000 \\
\hline Privacy & 6.143 & 0.000 & 8.830 \\
\hline Availability & 2.214 & 0.553 & 0.000 \\
\hline Scalability & 1.625 & 0.000 & 1.625 \\
\hline Compliance & 2.133 & 0.536 & 0.000 \\
\hline Storage Location & 0.320 & 0.000 & 1.999 \\
\hline Simplicity & 0.051 & 0.000 & 0.260 \\
\hline $\mathrm{S}^{\prime}$ & 3.574 & 1.082 & 3.572 \\
\hline
\end{tabular}


Depending on the value of relative closeness of the alternative solutions (A1, A2, A3) to the ideal solution $\left(C_{i}{ }^{*}\right)$ the ranking of these alternatives is identified. $C_{i}{ }^{*}$ for three alternatives are $\{0.2363,0.071,0.2361\}$. As seen from this example, A1 and A3 perform almost similar at these attributes due to similar $\mathrm{C}_{\mathrm{i}}{ }^{*}$. In this case establishing a trade-off strategy is most relevant as the final decision can be now based purely on business performance metrics. In other cases, especially when there is a substantial difference in $\mathrm{C}_{\mathrm{i}}{ }^{*}$, a trade-off strategy is mandatory, since a customer can judge the level of compromise that is to be made on returns to be expected. Trade-off are necessary as the best possible solution based on technical attributes might not be the most profitable as per business value and vice versa.

\subsection{Evaluation of Alternatives based on Business Performance Metrics}

This step expects organizations using TrAdeCIS to identify and prioritize BPMs for measuring expected return in terms of business value for each alternative. The process of ranking each of the available alternative solutions (here, A1, A2, A3), per factor or BPM, is based on the experience of organization, and the market history of the service or cloud-solution. For example, if the market history of alternative A1 is better than A3, A1 will be ranked higher for the considered factor.

As obtained during the discussion with $C 2$ the BPMs are migration time, cost reduction, and workload versus utilization. These are the only factors by which $C 2$ decided to evaluate the business value of the available alternatives as $C 2$ planned to serve the peak load requirements with minimum cost. Also, as this service is very critical, the business migration time should be the least possible, and critical workloads should be handled by the service provider by prioritizing resources. C2 identified that its cost reduction is twice as relevant as migration time. Remaining relevant priorities as identified by $C 2$ for these factors are shown in Tab. 7.

Table 7. Relative Priorities of BPMs

\begin{tabular}{|l|l|l|l|}
\hline $\begin{array}{l}\text { Business } \\
\text { Performance Metrics }\end{array}$ & Migration Time & Cost Reduction & Workload vs. Utilization \\
\hline Migration Time & 1 & $1 / 2$ & $1 / 3$ \\
\hline Cost Reduction & 2 & 1 & $1 / 3$ \\
\hline $\begin{array}{l}\text { Workload vs. Utiliza- } \\
\text { tion }\end{array}$ & 3 & 3 & 1 \\
\hline
\end{tabular}

\subsection{Trade-off-based Decision using ANP}

The ranked alternatives obtained in previous step of TrAdeCIS using TOPSIS, are now evaluated with respect to BPMs identified and ranked by the C2. As shown in Fig. 2 in ANP factors and alternative solutions are represented as nodes and inter-connections between them are marked with their relative importance, which is obtained by pair-wise comparison of each node. In this example, the decision is to be made for alternatives A1 and A3 as they scored same when evaluated using TOPSIS.

Following these steps as explained in Sec. 3.4, the normalized Eigen vector is calculated and priorities are found by TrAdeCIS. Hence the obtained unweighted super 


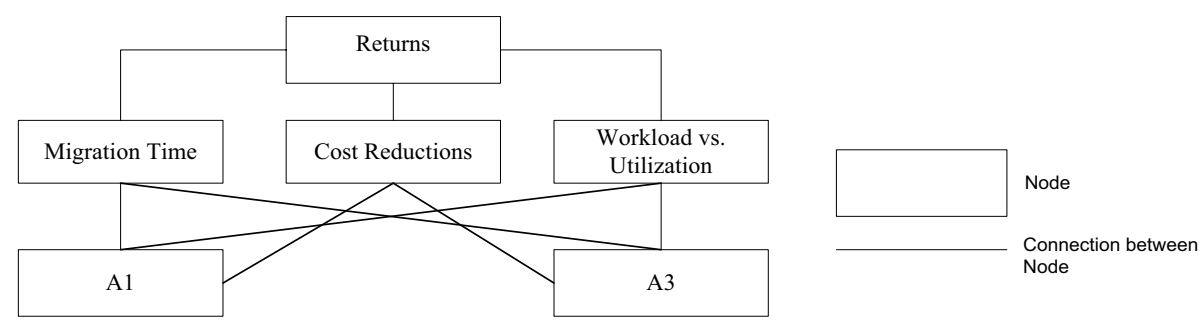

Fig. 2. Connection of Nodes in ANP

matrix is shown in Tab. 8. After normalizing the unweighted super matrix, the limit matrix is obtained as shown in Tab. 9. In ANP each alternative is evaluated independently of other alternatives. Now A3 gains higher priority owing to its high ranking in cost reductions, which overrule the high performance of A1 in the other two attributes (performance of alternatives in each of the attribute in Tab. 5). Therefore, A3 gives higher returns than A1 - it is a better solution in terms BPMs (migration time). cost reductions, and workload vs. utilization). However, as proven by TOPSIS A1 is a better alternative with respect to attributes important for the service. Now, if C2 desires to change the priorities of BPMs it can happen that A1 is again chosen. If this happens then the best technical solution will be chosen at a trade-off of return value. On the other hand, if A3 is chosen then the solution with best return value will be chosen at a trade-off of technical specifications.

Table 8. Values Obtained in Unweighted Super Matrix

\begin{tabular}{|l|l|l|l|l|l|l|}
\hline$-/-$ & Returns & $\begin{array}{l}\text { Migra- } \\
\text { tion Time }\end{array}$ & $\begin{array}{l}\text { Cost } \\
\text { Reduction }\end{array}$ & $\begin{array}{l}\text { Workloadvs. } \\
\text { Utilization }\end{array}$ & A1 & A3 \\
\hline Returns & 1 & 0 & 0 & 0 & 0 & 0 \\
\hline Migration Time & 16 & 1 & 0 & 0 & 75 & 13 \\
\hline Cost Reduction & 25 & 0 & 1 & 0 & 13 & 75 \\
\hline $\begin{array}{l}\text { Workload vs. Utiliza- } \\
\text { tion }\end{array}$ & 59 & 0 & 0 & 1 & 13 & 13 \\
\hline A1 & 0 & 50 & 20 & 67 & 1 & 0 \\
\hline A3 & 0 & 50 & 80 & 33 & 0 & 1 \\
\hline
\end{tabular}

Table 9. Values Obtained in Limit Matrix for Returns

\begin{tabular}{|l|l|l|l|l|l|l|}
\hline$-/-$ & Returns & $\begin{array}{l}\text { Migra- } \\
\text { tion Time }\end{array}$ & $\begin{array}{l}\text { Cost } \\
\text { Reduction }\end{array}$ & $\begin{array}{l}\text { Workloadvs. } \\
\text { Utilization }\end{array}$ & A1 & A3 \\
\hline Returns & 0 & 0 & 0 & 0 & 0 & 0 \\
\hline Migration Time & 0 & 18 & 18 & 18 & 0 & 0 \\
\hline Cost Reduction & 0 & 26 & 26 & 26 & 0 & 0 \\
\hline $\begin{array}{l}\text { Workload vs. Utiliza- } \\
\text { tion }\end{array}$ & 0 & 6 & 6 & 6 & 0 & 0 \\
\hline A1 & 36 & 0 & 0 & 0 & 18 & 18 \\
\hline A3 & 64 & 0 & 0 & 0 & 32 & 32 \\
\hline
\end{tabular}




\section{Summary, Conclusions, and Future Work}

This paper has determined and discussed the existing gap between adopting cloud services and evaluating the impact cloud-services will have on business processes and organization. To fill this gap the concept of establishing a trade-off strategy is introduced — the new TrAdeCIS methodology — by which an organization can evaluate available alternative cloud-based solution based on the impact selected alternative will have on business. To establish this trade-off strategy two multi-attribute decision analysis methods are applied: TOPSIS and ANP. While TOPSIS is used to rank alternative solutions based on attributes from the technical perspective, ANP identifies a trade-off strategy based on returns expected. Thus, TrAdeCIS quantifies this process of decision making for a cloud adoption by (a) identifying relevant attributes and their relative importance, (b) ranking attributes on the basis of requirements, and (c) establishing the trade-off strategy on the basis of returns expected. This paper also illustrates TrAdeCIS based on survey results collected from organizations who have adopted or plan to adopt cloud-based solutions for their IT requirements.

It can be concluded that the current ad-hoc process of cloud adoption in organizations can be replaced with the quantitative methodology of TrAdeCIS. This approach developed fills the gap of evaluating cloud-based solutions not only from the technical perspective, but also from the view of impact it will have on the organization.

The next step of this work is to implement TrAdeCIS as a working prototype, which will be tested and evaluated with further organizations, who plan to adopt cloud-based solution for their advanced IT needs. This will help to evaluate the impact of TrAdeCIS in full and in such a decision making process of these organizations, all in comparison to existing, though, functionally restricted related work.

Acknowledgments. This work was partly funded by FLAMINGO, the Network of Excellence Project ICT-318488, supported by the European Commission under its Seventh Framework Programme.

\section{References}

1. M. Armbrust, A. Fox, R. Grith, A. Joseph: A View of Cloud Computing of Cloud; Communications of the ACM, Vol. 53, No. 4, pp. 50-58, New York, USA, April, 2010

2. P. Beserra, A. Camara, R. Ximenes, A. B. Albuquerque, N. C. Mendonca: Cloudstep: A Step-by-Step Decision Process to Support Legacy Application Migration to Cloud; 6th International Workshop on the Maintenance and evolution of Service-Oriented and CloudBased Systems (MESOCA), pp. 7-16, IEEE, Trento, Italy, 2012

3. L. Blaxter, C. Hughes, M. Tight: How to Research; McGraw-Hill International, 2010

4. V. Chang, G. Wills, R. J. Walters, W. Curie: Towards a Structured Cloud ROI: The University of Southampton Cost-Saving and User Satisfaction Case Studies; Sustainable Green Computing: Practise, Methodologies and Technologies, pp. 179-200, IGI Global, 2012

5. M. B. Chhetri, Q. B. Vo, R. Kowalczyk: Policy-based Automation of SLA Establishment for Cloud Computing Services; IEEE/ACM 12th International Symposium on Cluster, Cloud, and Grid Computing (CCGrid), pp. 164-171, IEEE, Ottawa, Canada, 2012 
6. H. Deng, C. Yeh, R. Wills: Inter-company Comparison Using Modified TOPSIS with Objective Weights; Computers and Operational Research, Vol. 27, No. 10, pp. 963-973, 2000

7. A. Ferrer, F. Hernandez, J. Tordsson, E. Elmroth, C. Zsigri, R. Sirvent, J. Guitart, R. Badia, K. Djemame, W. Ziegler, T. Dimitrakos, S. Nair, G. Kousiouris, K. Konstanteli, T. Varvarigou, B. Hudzia, A. Kipp, S. Wesner, M. Corrales, N. Forgo, T. Sharif, C. Sheridan: OPTIMIS: A Holistic Approach to Cloud Service Provisioning; Future Generation Computer Systems, Vol. 28, No. 1, pp. 66-77, 2012

8. J. O. Fito, M. Macias, F. Julia, J. Guitart: Business-Driven IT Management for Cloud Computing Providers; 4th International Conference on Cloud Computing Technology and Science (CloudCom), pp. 193-200, IEEE, Taipei, Taiwan, 2012

9. P. Geczy, N. Izumi, K. Hasid:. Cloudsourcing: Managing Cloud Adoption; GlobalJournal of Business Research, Vol. 6, No. 2, pp. 57-70, 2012

10. D. Greenwood, A. Khajeh-Hosseni, J. Smith, I. Sommerville: The Cloud Adoption Toolkit: Addressing the Challenges of Cloud Adoption in Enterprise; Arxiv preprint, arXiv:1003.3866, 2010

11. A. Khajeh-Hosseini, D. Greenwood, I. Sommerville: Cloud Migration: A Case Study of Migrating an Enterprise IT System to IaaS; 3rd International Conference on Cloud Computing (CLOUD), pp. 450-457, IEEE, Miami, Florida, USA, 2010

12. C. Hwang, K. Yoon: Multi Attribute Decision Making: Methods and Applications; Springer Verlag, Berlin, Germany, 1981

13. A. Li, X. Yang, S. Kandula, M. Zhang: Cloudcmp: Comparing Public Cloud Providers; ACM SIGCOMM Conference on Internet Measurement, pp. 1-14, ACM, Melbourne, Australia, 2010

14. M. Menzel, M. Schoenherr, S. Tai: The (MC2)2 Criteria, Requirements and a Software Prototype for Cloud Infrastructure Decisions; Software: Practice and Experience, Wiley Online Library, 2011

15. M. Niemira, T. Saaty: An Analytic Network Process Model for Financial-crisis Forecasting; International Journal of Forecasting, Vol. 20, No. 4, pp. 573-587, 2004

16. P. Saripalli, G. Pingali: MADMAC: Multiple Attribute Decision Methodology for Adoption of Clouds; 4th International Conference on Cloud Computing (CLOUD), pp. 316-323, IEEE, Washington DC, USA, July 2011

17. T. Saaty: Fundamentals of the Analytic Network Process-dependence and Feedback in Decision-making with a Single Network; Journal of Systems Science and Systems Engineering, Vol. 13, No. 2, pp. 129-157, 2004

18. M. Sedaghat, F. Hernandez, E. Elmroth: Unifying Cloud Management: Towards Overall Governance of Business Level Objectives; IEEE/ACM 11th International Symposium on Cluster, Cloud, and Grid Computing (CCGrid), pp. 591-597, Newport Beach, CA, USA, May 2011

19. N. A. Sultan: Reaching for the "Cloud": How SMEs can Manage; International Journal of Information Management, Vol. 31, No. 3, pp. 272-278, 2011

20. J. Wang, S. Liu, J. Zhan: An extension TOPSIS for Fuzzy MCDM Based on Vague Set Theory; Journal of Systems Science and Systems Engineering, Vol. 14, No. 1, pp. 73-84, March 2005

21. T. Wang, T. Chang: Application of TOPSIS in Evaluating Initial Training Aircraft under a Fuzzy Environment; Expert Systems with Applications, Vol. 33, No. 4, pp. 870-880, 2007

22. S. Zardari, R. Bahnsoon: Cloud Adoption: A Goal-Oriented Requirements Engineering Approach; 2nd International Workshop on Software Engineering for Cloud Computing, pp. 29-35, ACM, Honolulu, Hawaii, USA, 2011 